\title{
Remote Sensing and GIS Approach for Spatiotemporal Mapping of Ramganga Reservoir
}

\author{
Vaibhav Deoli* and Deepak Kumar \\ Department of Soil and Water Conservation Engineering, College of Technology, G.B. Pant \\ University of Agriculture and Technology, Pantnagar, India, 263145 \\ *Corresponding author
}

\section{Keywords \\ Landsat-8, NDVI, Ramganga reservoir, QGIS, spatiotemporal \\ Article Info \\ Accepted: \\ 10 April 2019 \\ Available Online: \\ 10 May 2019}

\section{A B S T R A C T}

Remote sensing is very useful to collect information about water resource and to manage it by satellite data. In this paper, study has been carried out for Ramganga reservoir using Landsat 8 imagery for spatiotemporal mapping. The imagery has been collected from 2013 to 2018 for pre-monsoon and post monsoon season. The reservoir, under study, is presently used for hydroelectric purpose and irrigation. Landsat-8 images which were cloud free has been taken for the study. The study is carried out on QGIS platform and Normalized Difference Vegetation Index (NDVI) has been used to map water spread area of the reservoir. Results of this study suggested that in pre-monsoon session, maximum water spread area of $59.81 \mathrm{~km}^{2}$ was in 2014 whereas year 2017 has shown minimum water spread area of $3.18 \mathrm{~km}^{2}$ for pre-monsoon session. In post monsoon session, year 2014 shows maximum water spread area of $68.53 \mathrm{~km}^{2}$ the reservoir whereas year 2016 shows minimum water spread area of $53.97 \mathrm{~km}^{2}$. The average water spread area of the reservoir in pre-monsoon was $40.01 \mathrm{~km}^{2}$ and in post-monsoon was $61.84 \mathrm{~km}^{2}$. The results also suggested that NDVI could be used with accuracy to extract water features and also the spread area.

\section{Introduction}

Water is an indispensable part of ecosystem for the sustainability of life. Surface water is a critical resource in semi-arid areas. Inland surface water include sea, rivers, ponds, lakes, reservoirs and canals. It is important to monitor water bodies for adequate ecosystem balance and for maintaining climate variation, hydrological cycle, carbon cycle etc. It is not only important for human, rather it is equally important for all other forms of life. As per as reservoir management is concerned, monitoring of temporal and spatial variation of water spread is important for proper management of irrigation and hydroelectric generation.

Identification of water bodies are equally important for agriculture scheduling, flood estimation, wetland, drought land estimation of ground water and many more. Accurate mapping of surface water is significant to describe its spatial - temporal variation. 
Landsat imagery are widely used by researcher for various studies on earth surface (Roy et al., 2014; Li et al., 2014; Santos et al., 2017; Abdelaziz et al., 2018) coupled with remote sensing and geographical information system.

Since, the resolution of Landsat- 8 is more than that of Landsat-7, hence for natural resource estimation and management, it is better to use the formal (Jarchow et al., 2018; Baumann et al., 2018).

Remote sensing technology is used to monitor water resources also. Remote sensing application in water resource includes change in surface water resource, water quality assessment and monitoring flood hazard/damage assessment and management and water-borne disease epidemiology.

Till now, there is number of technique for water extraction using satellite imagery. Among these, spectral index technique has been widely using because it is easy to use. In spectral technique, normalized difference vegetation index (NDVI), normalized difference water index (NDWI), water ratio index (WRI), are mostly used indexes.

Change detection in water bodies has been examined extensively by different researchers from all over the words. Ross S. Lunetta et al., (2006) detected land cover changes by NDVI index. Authors suggested NDVI index with no cost Landsat data provide high quality continuous time series data to monitoring land cover change detection and monitoring water bodies. Bhandari et al., (2012) used normalized difference vegetation index (NDVI) for feature extraction. They suggest NDVI is a highly useful to detect features in earth surface. A. K. Bhandari (2014) successfully worked on improved feature extraction by satellite imagery using NDVI and NDWI index. They suggested that NDVI and NDWI are out do for spectral signature of different objects such as vegetation index and water body classification presented in the satellite image. Kavyashree M.P (2016) used NDVI to detect wetland mapping and change detection. They compare Landsat images of 1998 with LISS III images of 2008-09 to detect the changes in land cover and wetland changes in that area. Yang Shao et al., (2016) used NDVI to detect land cover classification. Tri Dev Acharya et al., (2016) used Landsat 8 imagery to detect change in water using a J48 decision tree which is an open source and identify water bodies using reflectance band of Landsat-8 images.

The objective of present study is to map yearly change in Ramganga reservoir of Uttarakhand. This study include detecting changes in water spread area of Ramganga reservoir in pre-monsoon and post-monsoon period by incorporating NDVI index on Landsat 8 imagery using QGIS platform for 5 years from 2013 to 2018.

\section{Materials and Methods}

\section{Study location and data collection}

The study was conducted for Ramganga reservoir. It has latitude of $29^{0} 33^{\prime} \mathrm{N}$ and longitude of $78^{0} 45^{\prime}$ E located in Cordate Nation Park range near Ramnagar city of Uttarakhand state of India (Fig. 1). The study area is located in Tarai region of Uttarakhand in the foothills of Himalaya with an elevation of $347 \mathrm{~m}$ above mean sea level.

The temporal Landsat- 8 imagery of this region has been taken from Earth Explorer website. Landsat-8 imagery which was cloud free has been taken from December 2013 to June 2018. For every year, two raster images have been taken, one for pre- monsoon and another for post monsoon. In pre- monsoon, raster images of the study area have been 
taken in month of May or June and for postmonsoon session images, it has been taken in month of November or December. Table 1 shows acquisition date of Landsat- 8 imagery taken for this study. The specification of collected Landsat- 8 imagery is given in Table 2 .

\section{NDVI index for mapping water body}

For mapping of water body, different ratios can be used for raster calculation to extract information. In this study, NDVI technique is used to extract reservoir. Firstly, radiometric calibration was performed to converting images in different Landsat- 8 bands. After pre-processing, the images were used to calculate NDVI, which were than reclassified based on threshold for water and non-water. A model was developed in Q-GIS software for change detection as shown in Figure 2.

Normalized Difference Vegetation Index (NDVI) is a technique used to estimate land cover area, built-up area, water cover area, open area, forest by combination of few band of satellite imagery.

The value of NDVI varies from -1 to +1 . Generally negative values including zero value of NDVI represent water cover area and positive values of NDVI stand for non-water cover area. In general, NDVI is calculated as per Equation 1.

$N D V I=\frac{N I R-R E D}{N I R+R E D}$

Where, NIR stand for Near Infra-Red; RED represent the red spectrum. In the present study, Landsat-8 imagery has been used, and thus, band 5 represents NIR and Band 4 represents RED. Thus, Equation 2 has been used for NDVI estimation in the present study.

$$
N D V I=\frac{B 5-B 4}{B 5+B 4}
$$

\section{Results and Discussion}

In this section, the results obtained for spatial variation of water spread area for the duration from 2013 to 2018 of Ramganga reservoir has been discussed. The results of the spatial variability in reservoir water spread area has been studied both for pre monsoon as well as post monsoon period. Since NDVI is one of the well-established index to extract features on the earth, the same has been used for water body extraction.

The mapping of water body for pre monsoon season using NDVI index has been shown in Figure 3. Since the images of pre monsoon months of 2013 has full of cloud, thus, for 2013, the results of the same has not been shown in Figure 3. From this figure, it might be suggested that the water spread area during the pre-monsoon period from 2014 to 2017 has decreased. Table 3 suggested that the decrease in water spread area from 2014 to 2015 was $3.11 \mathrm{~km}^{2}$, while the decrease in water spread for 2016 was further reduced to $36.14 \mathrm{Km}^{2}$ as compared to 2014. The lowest water spread area for the study period was observed during 2017. During 2017, the water spread was only $3.18 \mathrm{~km}^{2}$. This might be due to less rainfall in 2017 as compared to other years under study.

The spatial water spread mapping of postmonsoon period is shown in Figure 4. The estimated water spread area of the same has also been numerically shown in Table 3 . The calculated surface area of the reservoir in post monsoon session were $67.01 \mathrm{~km}^{2}, 68.53 \mathrm{~km}^{2}$, $59 \mathrm{~km}^{2}, 53.97 \mathrm{~km}^{2}$ and $60.67 \mathrm{~km}^{2}$ for years 2013, 2014, 2015, 2016 and 2017 respectively. From the post monsoonal results of Figure 2 and Table 1, it might be suggested that the water spread area was lowest during 2016 and highest during 2014. The variation in water spread area might be due to weak monsoon in that period and also due to excess 
demand of reservoir water in downstream of the reservoir.

From result based on satellite Landsat- 8 imagery it is also clear that in both, premonsoon and post monsoon the average water surface area of the Ramganga reservoir is decreasing. Year 2014 shows maximum water spread area where as in year 2016 shows minimum water spread area. In summer session the calculated surface area of the reservoir were $59.81 \mathrm{~km}^{2}, 56.7 \mathrm{~km}^{2}, 23.67$ $\mathrm{km}^{2}, 3.18 \mathrm{~km}^{2}$ and $56.7 \mathrm{~km}^{2}$ for years 2014 , 2015, 2016, 2017 and 2018 respectively. In summer year 2014 shows maximum water surface area where as in year 2017 water surface area was very low.

Table.1 Acquisition dates of Landsat 8 imagery for the study period

\begin{tabular}{|c|c|c|}
\hline Year & Pre-monsoon & Post-monsoon \\
\hline $\mathbf{2 0 1 3}$ & & $16-12-2013$ \\
\hline $\mathbf{2 0 1 4}$ & $10-06-2014$ & $03-12-2014$ \\
\hline $\mathbf{2 0 1 5}$ & $28-05-2015$ & $22-12-2015$ \\
\hline $\mathbf{2 0 1 6}$ & $14-05-2016$ & $24-12-2016$ \\
\hline $\mathbf{2 0 1 7}$ & $02-06-2017$ & $11-12-2017$ \\
\hline $\mathbf{2 0 1 8}$ & $20-05-2018$ & $12-11-2018$ \\
\hline
\end{tabular}

Table.2 Specification of Landsat-8 Imagery

\begin{tabular}{|c|c|c|c|}
\hline Band & Description & Wavelength(micro meters) & Resolution(meters) \\
\hline $\mathbf{1}$ & Violet-Deep Blue & $0.43-0.45$ & 30 \\
\hline $\mathbf{2}$ & Blue & $0.45-0.51$ & 30 \\
\hline $\mathbf{3}$ & Green & $0.53-0.59$ & 30 \\
\hline $\mathbf{4}$ & Red & $0.64-0.67$ & 30 \\
\hline $\mathbf{5}$ & Near Infrared & $0.85-0.88$ & 30 \\
\hline $\mathbf{6}$ & Shortwave Infrared & $1.57-1.65$ & 30 \\
\hline $\mathbf{7}$ & Shortwave Infrared & $2.11-2.29$ & 30 \\
\hline $\mathbf{8}$ & Panchromatic & $0.50-0.68$ & 15 \\
\hline $\mathbf{9}$ & Cirrus Clouds & $1.36-1.38$ & 30 \\
\hline $\mathbf{1 0}$ & Thermal Infrared & $10.62-11.19$ & 30 \\
\hline $\mathbf{1 1}$ & Thermal Infrared & $11.50-12.51$ & 30 \\
\hline
\end{tabular}

Table.3 Calculated water spread area $\left(\mathrm{km}^{-2}\right)$ for the study period for Ramganga reservoir

\begin{tabular}{|c|c|c|}
\hline Year & Pre-monsoon $\left.\mathbf{( k m}^{\mathbf{2}}\right)$ & Post-monsoon $\left.\mathbf{( k m}^{\mathbf{2}}\right)$ \\
\hline $\mathbf{2 0 1 3}$ & -- & 67.01 \\
\hline $\mathbf{2 0 1 4}$ & 59.81 & 68.53 \\
\hline $\mathbf{2 0 1 5}$ & 56.7 & 59 \\
\hline $\mathbf{2 0 1 6}$ & 23.67 & 53.97 \\
\hline $\mathbf{2 0 1 7}$ & 3.18 & 60.67 \\
\hline $\mathbf{2 0 1 8}$ & 56.7 & 61.1 \\
\hline
\end{tabular}


Fig.1 Location of Ramganga Reservoir

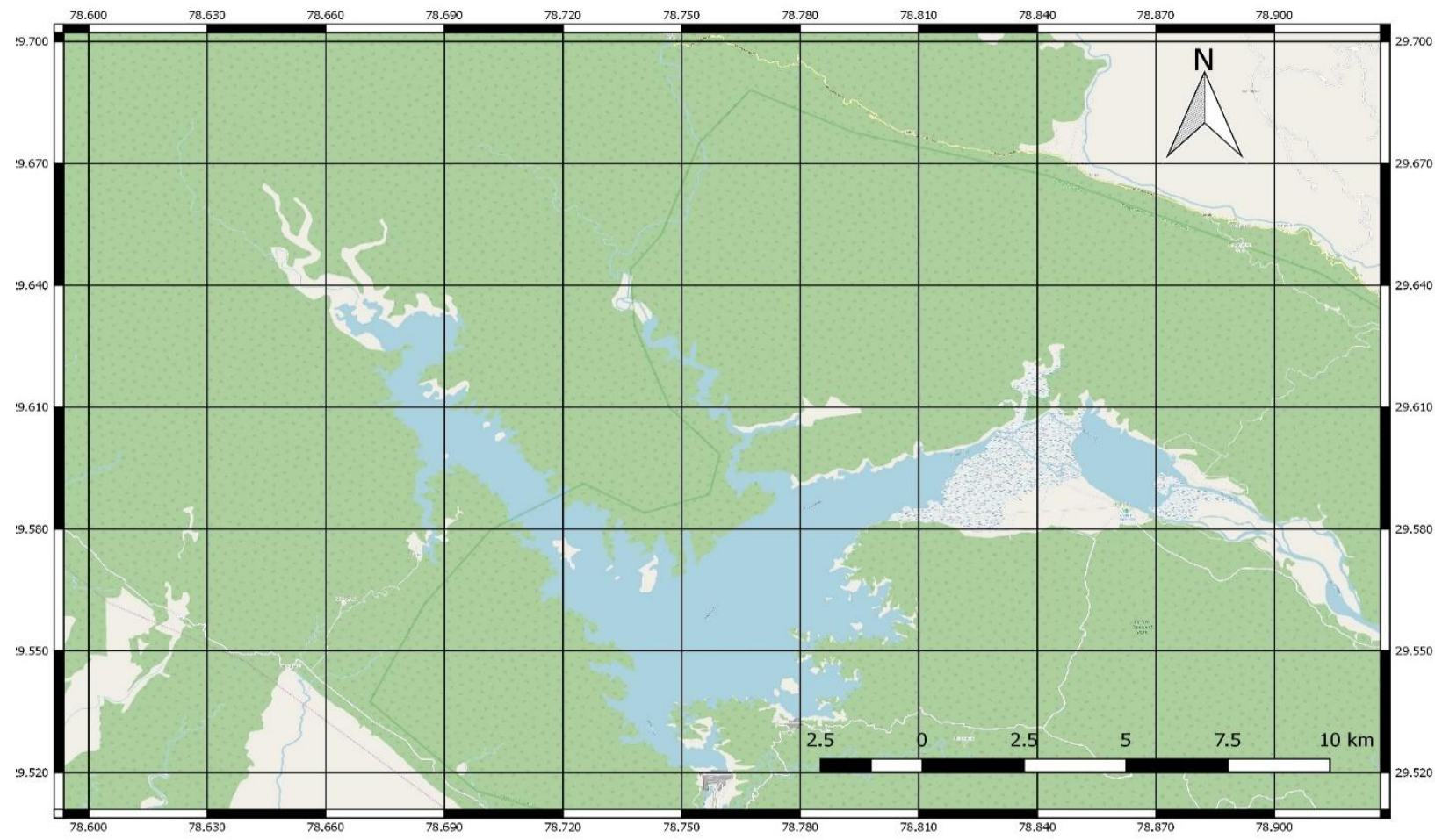

Fig.2 Flow chart for water body mapping using QGIS

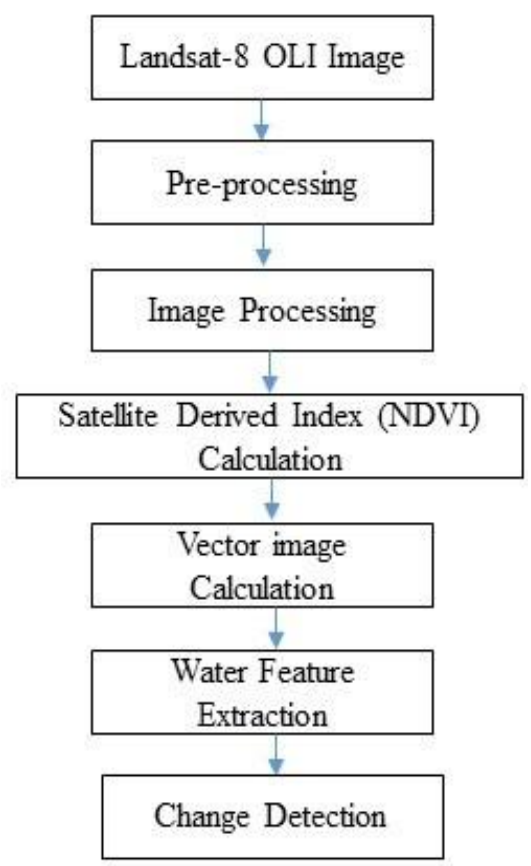


Fig.3 Water spread mapping of Ramganga reservoir during pre-monsoon period

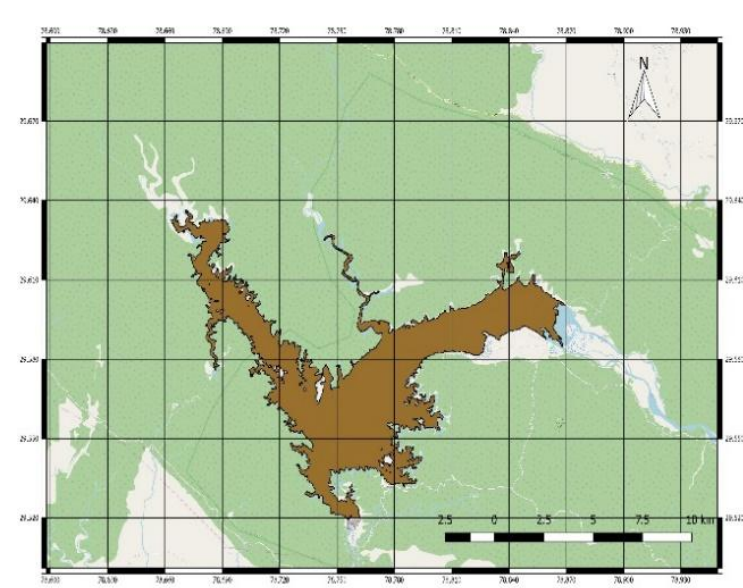

2014

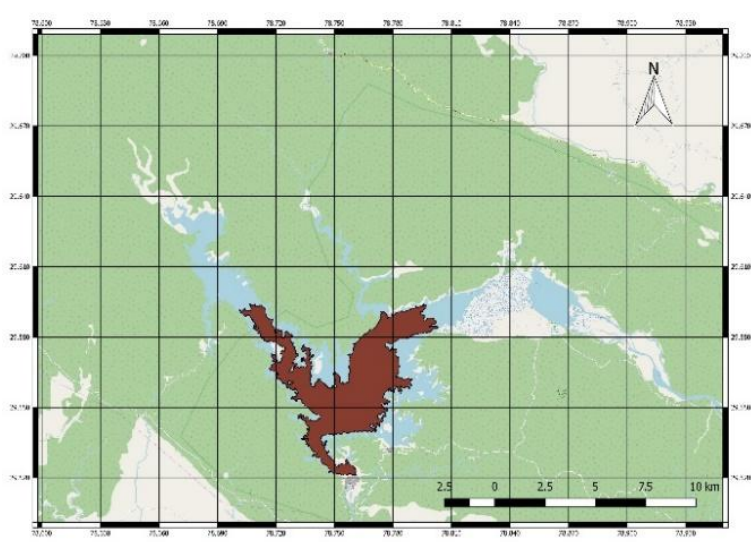

2016
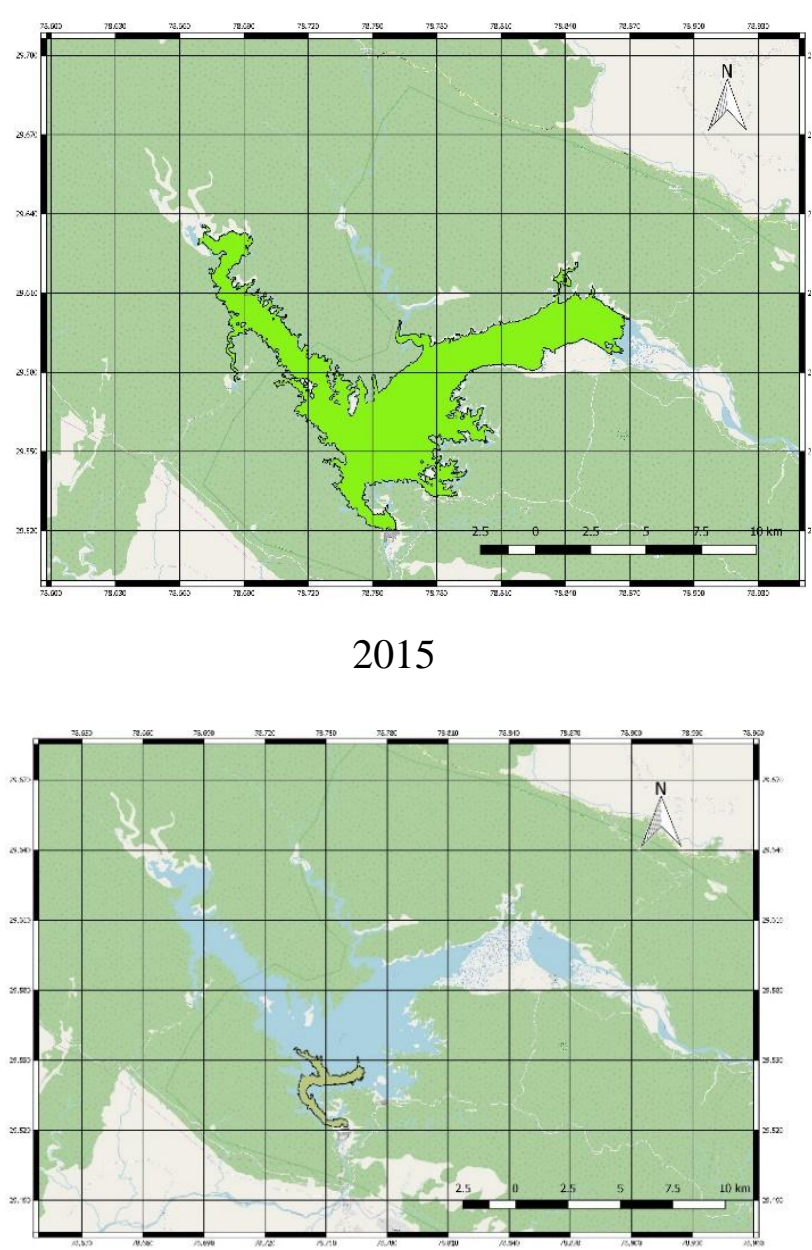

2017

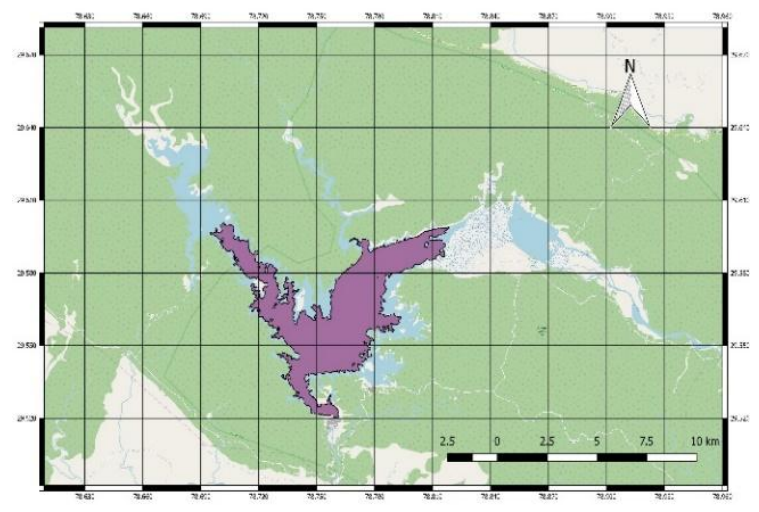

2018 
Fig.4 Water spread mapping of Ramganga reservoir during Post-monsoon period

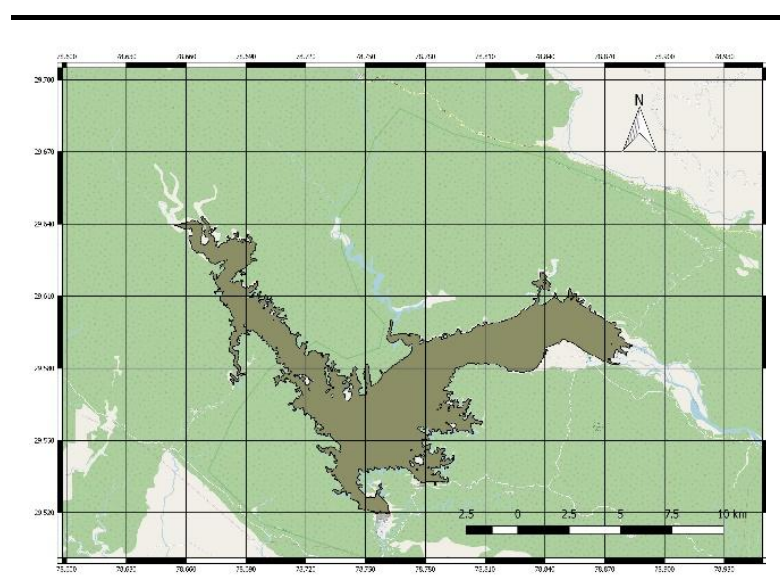

2013

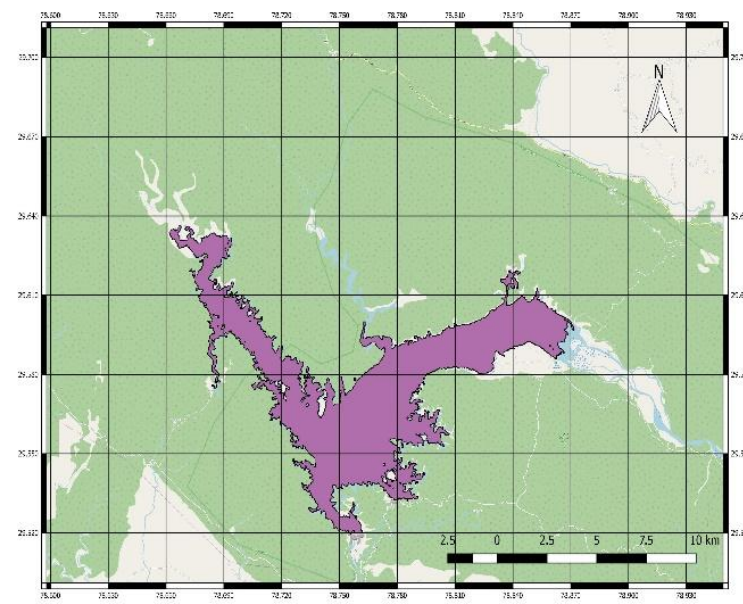

2015

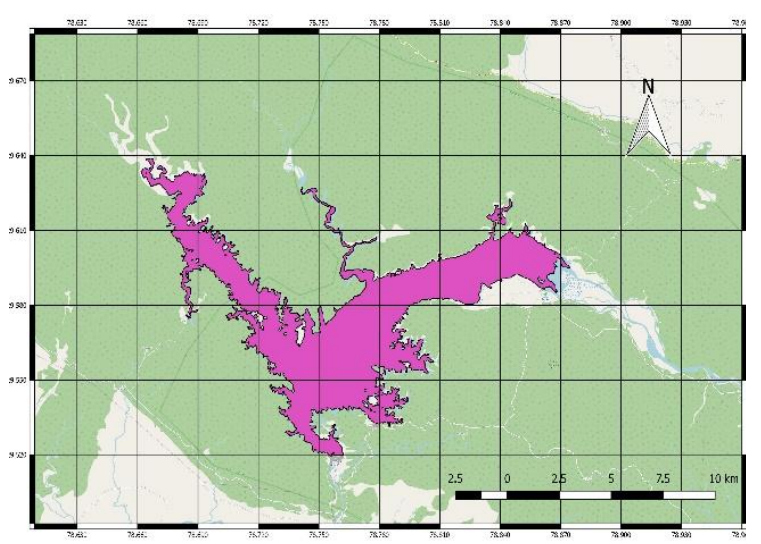

2017

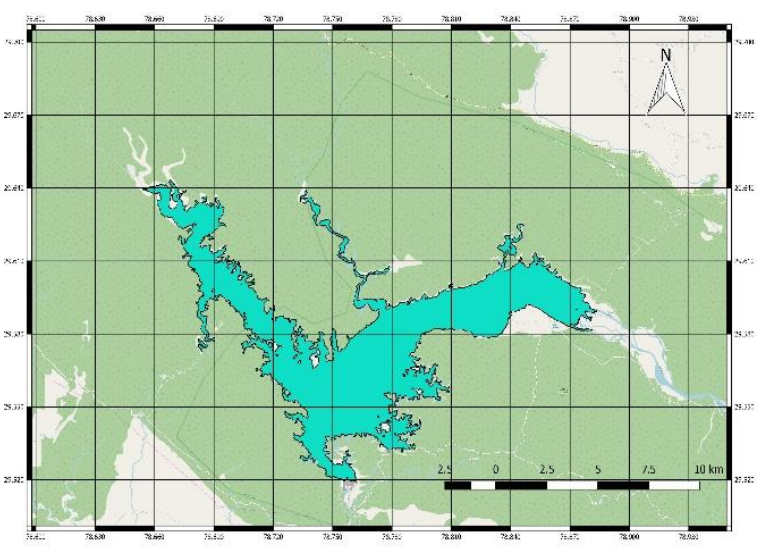

2014

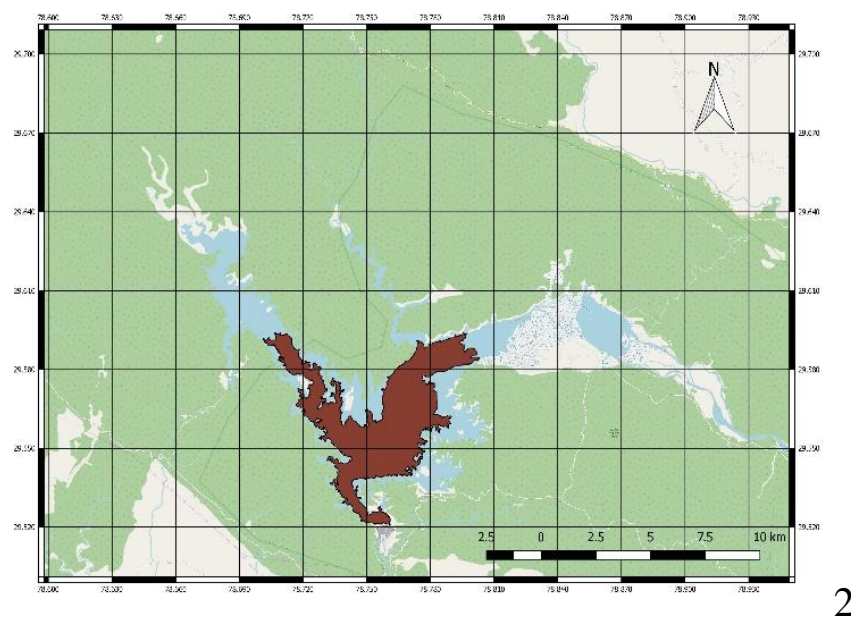

016

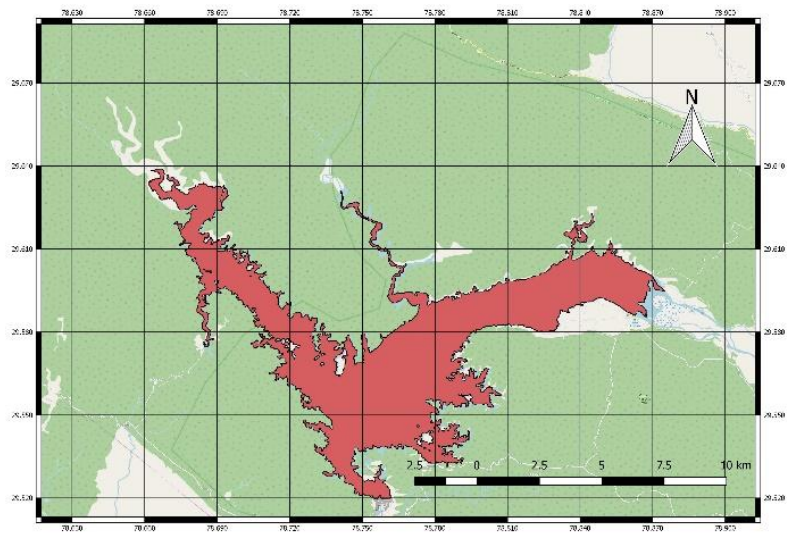

2018 
In conclusion, in this study, unsupervised index method was used to detect the change of Ramganga Reservoir in Ramnagar city using Landsat-8 data of 5 years from 2013 to 2018. For mapping of water body, NDVI has been used and the same has been incorporated in digital image to find the water spread area of Ram Ganga reservoir using QGIS. It could be concluded from the results that during the study period, the water spread area was maximum during 2014 for both pre and post monsoon. For pre-monsoon, the water spread area was $58.81 \mathrm{~km}^{2}$, while for post-monsoon, the water spread area was $68.53 \mathrm{~km}^{2}$. The results suggested that NDVI could be used with accuracy to extract water features and also the spread area.

\section{References}

Abdelaziz, R., El-Rahman, Y. A., and Wilhelm, S. (2018). Landsat-8 data for chromite prospecting in the Logar Massif, Afghanistan. Heliyon, 4(2), $\mathrm{e} 00542$.

Acharya, T. D., Lee, D. H., Yang, I. T., and Lee, J. K. (2016). Identification of water bodies in a Landsat 8 OLI image using a j48 decision tree. Sensors, 16(7), 1075.

Bhandari, A. K., Kumar, A., and Singh, G. K. (2012). Feature extraction using Normalized Difference Vegetation Index (NDVI): A case study of Jabalpur city. Procedia technology, 6, 612-621.

Bhandari, A. K., Kumar, A., and Singh, G. K. (2015). Improved feature extraction scheme for satellite images using NDVI and NDWI technique based on DWT and SVD. Arabian Journal of Geosciences, 8(9), 6949-6966.

Baumann, M., Levers, C., Macchi, L., Bluhm, H., Waske, B., Gasparri, N. I., and Kuemmerle, T. (2018). Mapping continuous fields of tree and shrub cover across the Gran Chaco using Landsat 8 and Sentinel-1 data. Remote sensing of environment, 216, 201-211.

Jarchow, C. J., Didan, K., Barreto-Muñoz, A., Nagler, P. L., and Glenn, E. P. (2018). Application and Comparison of the MODIS-Derived Enhanced Vegetation Index to VIIRS, Landsat $5 \mathrm{TM}$ and Landsat 8 OLI Platforms: A Case Study in the Arid Colorado River Delta, Mexico. Sensors, 18(5), 1546.

Kavyashree, M., and Ramesh, H. (2016). Wetland mapping and change detection using remote sensing and GIS. International Journal of Engineering Science, 6(8), 2356.

Li, P., Jiang, L., and Feng, Z. (2014). Crosscomparison of vegetation indices derived from Landsat-7 enhanced thematic mapper plus (ETM+) and Landsat-8 operational land imager (OLI) sensors. Remote Sensing, 6(1), 310-329.

Lunetta, R. S., Knight, J. F., Ediriwickrema, J., Lyon, J. G., and Worthy, L. D. (2006). Land-cover change detection using multi-temporal MODIS NDVI data. Remote sensing of environment, 105(2), 142-154.

Roy, D. P., Wulder, M. A., Loveland, T. R., Woodcock, C. E., Allen, R. G., Anderson, M. C., and Scambos, T. A. (2014). Landsat-8: Science and product vision for terrestrial global change research. Remote sensing of Environment, 145, 154-172.

Santos, M. M., Machado, I. E. S., Carvalho, E. V., Viola, M. R., and Giongo, M. (2017). Estimation of forest parameters in Cerrado area from OLI Landsat 8 sensor. Floresta, 47(1), 75-83.

Shao, Y., Lunetta, R. S., Wheeler, B., Iiames, J. S., and Campbell, J. B. (2016). An evaluation of time-series smoothing algorithms for land-cover classifications using MODIS-NDVI multi-temporal data. Remote Sensing of Environment, $174,258-265$. 
Xu, D., and Guo, X. (2014). Compare NDVI extracted from Landsat 8 imagery with that from Landsat 7 imagery. American Journal of Remote Sensing, 2(2), 10-14.

\section{How to cite this article:}

Vaibhav Deoli and Deepak Kumar. 2019. Remote Sensing and GIS Approach for Spatiotemporal Mapping of Ramganga Reservoir. Int.J.Curr.Microbiol.App.Sci. 8(05): 775783. doi: https://doi.org/10.20546/ijcmas.2019.805.092 